\title{
Analisis Tingkat Efektivitas Kerja pada Mesin Auto Hanger dengan Menggunakan Metode Overall Equipment Effectiveness (OEE)
}

\author{
Melani Magdalena Hutabarat ${ }^{1}$, Ahmad Muhsin ${ }^{1}$ \\ ${ }^{1}$ Jurusan Teknik Industri, Fakultas Teknik Industri, UPN "Veteran” Yogyakarta \\ Jl. SWK 104, Condongcatur, Depok, Sleman, Yogyakarta \\ email:ahmad.muhsin@upnyk.ac.id \\ doi: https://doi.org/10.31315/opsi.v13i1.3468
}

Received: $11^{\text {th }}$ June 2020; Revised: 29 th June 2020; Accepted: $29^{\text {th }}$ June 2020;

Available online: $30^{\text {th }}$ June 2020; Published regularly: June 2020

\begin{abstract}
The packing plant department 1 is still lacking in meeting production productivity targets. Therefore, the availability of raw materials and the condition of machinery and equipment is important to consider so that product productivity can be optimized. Three aspects affect the effectiveness of the machine in the packing department, namely productive time, work speed of the machine, and the quality of the product produced. The purpose of this study is to measure the effectiveness of the auto hanger engine by using the Overall Equipment Effectiveness (OEE) method to obtain the value of availability, performance efficiency, and rate of quality. The results obtained from OEE calculations are expected to be an evaluation of improvements in effectiveness that will be generated in the future. Based on the results of research that overall equipment effectiveness on the three machines has not reached world-class standards, which is $>85 \%$. The availability value on the three machines also still does not meet the world-class standard, which is $>90 \%$. The performance of rate values on the three machines also still does not meet world-class standards, which is $>95 \%$. The availability value on the three machines also still does not meet the world-class standard, which is $>99 \%$.
\end{abstract}

Keywords: OEE; Machinery; Department of Plant

\begin{abstract}
ABSTRAK
Departemen packing plant Imasih terbilang kurang dalam memenuhi target produktivitas produksi. Oleh sebab itu maka ketersediaan bahan baku dan kondisi mesin dan peralatan penting untuk diperhatikan agar produktivitas produk dapat optimal. Terdapat tiga aspek yang berpengaruh terhadap efektivitas mesin dalam departemen packing, yaitu waktu produktif, kecepatan kerja mesin, dan kualitas produk yang dihasilkan. Tujuan penelitian ini adalah mengukur efektivitas mesin auto hanger dengan menggunakan metode Overall Equipment Effectiveness (OEE) untuk mendapatkan nilai availability, performance efficiency dan rate of quality. Hasil yang didapatkan dari perhitungan OEE diharapkan dapat menjadi evaluasi perbaikan dalam efektivitas yang akan dihasilkan dikemudian hari. Berdasarkan hasil penelitian bahwa overall equipment effectiveness pada ketiga mesin belum mencapai standar world class, yaitu > 85\%. Nilai availability pada ketiga mesin juga masih belum memenuhi standar world class, yaitu $>90 \%$. Nilai performance of rate pada ketiga mesin juga masih belum memenuhi standar world class, yaitu > 95\%. Nilai availability pada ketiga mesin juga masih belum memenuhi standar world class, yaitu $>99 \%$.
\end{abstract}

Kata Kunci: OEE; Mesin; Departemen Plant

\section{PENDAHULUAN}

PT XYZ merupakan suatu perusahaan yang bergerak di bidang minuman kesehatan. PT Sari Enesis Indah menghasilkan berbagai produk minuman serbuk yang dikemas dalam bentuk kemasan sachet. Produk tersebut meliputi adem sari, tesona, esquiz fizz, dan scrubber. Produk ini dibagi kedalam 2 lokasi plant produksi yang sudah memenuhi standar pengopersian.

Departemen packing merupakan departemen produk jadi yang dipisah untuk setiap produknya. Bahan baku yang digunakan adalah produk kemasan sachet yang telah dilakukan analisis oleh Quality Control. Kemasan sachet tersebut kemudian diproses agar dapat menempel pada hanger yang telah tersedia. Setiap hanger terdiri dari 24 kemasan 
sachet adem sari. Berat optimal dari satu hanger yaitu sekitar $211,4 \mathrm{~kg}-221,9 \mathrm{~kg}$. Produk akhir yang dihasilkan dalam proses produksi ini merupakan karton yang berisi 24 hanger didalamnya. Berat standar dari tiap karton yaitu 5,45 kg - 5,75 kg.

Pada proses packing plant 1 melibatkan 3 jalur lintasan packing. Setiap jalur memiliki mesin auto hanger yang terdiri dari beberapa auto hanger. Jalur lintasan ke 1 memiliki 3 mesin auto hanger yang terhubung oleh 1 conveyor. Jalur lintasan ke 2 memiliki 2 mesin auto hanger yang terhubung oleh 1 conveyor. Jalur lintasan ke 3 memiliki 2 mesin auto hanger yang terhubung oleh 1 conveyor.

Departemen packing plant 1masih terbilang kurang dalam memenuhi target produktivitas produksi. Oleh sebab itu maka ketersediaan bahan baku dan kondisi mesin dan peralatan penting untuk diperhatikan agar produktivitas produk dapat optimal. Terdapat tiga aspek yang berpengaruh terhadap efektivitas mesin dalam departemen packing, yaitu waktu produktif, kecepatan kerja mesin, dan kualitas produk yang dihasilkan.

Efektivitas mesin auto hanger dapat diukur melalui performa yang dihasilkan melalui pengukuran dengan menggunakan metode Overall Equipment Effectiveness (OEE) untuk mendapatkan nilai availability, performance efficiency dan rate of quality. Hasil yang didapatkan dari perhitungan OEE diharapkan dapat menjadi evaluasi perbaikan dalam efektivitas yang akan dihasilkan dikemudian hari.

Berdasarkan latar belakang masalah maka dapat diketahui bahwa terjadi produktivitas yang menurun diakibatkan rendahnya efektivitas kinerja mesin. Sehingga perumusan permasalahan yang ada pada departemen packing plant 1 di PT Sari Enesis Indah adalah bagaimana tingkat efektivitas mesin auto hanger dengan menggunakan metode Overall Equipment Effectiveness (OEE).

\section{LANDASAN TEORI}

Overall Equipment Effectiveness (OEE) merupakan salah satu aplikasi dari program Total Productive Maintenance (TPM) yang digunakan sebagai alat untuk menentukan tingkat efektivitas mesin (Wahyuni, 2015). Perencanaan dan pemeliharaan dapat menggunakan metode
RCM (Bangun, 2014). OEE adalah analisis hasil yang dapat dinyatakan sebagai rasio output aktual dari peralatan dibagi dengan output maksimum peralatan di bawah kondisi keadaan terbaik (Muhsin, 2016).

Pengukuran OEE biasanya digunakan sebagai indicator kinerja utama Key Performance Indicator (KPI) dalam implementasi lean manufacturing untuk meminimasi waste guna memberikan indicator (Ristyowati, Muhsin dan Nurani, 2017). Penggunaan OEE sebagai analisis performance indicator suatu departemen dapat dilakukan dalam periode waktu yang berbeda, seperti harian, mingguan, atau bulanan (Muhsin, 2016). Availability adalah rasio yang menunjukkan pemanfaatan waktu yang tersedia untuk kegiatan operasi mesin atau peralatan. Data yang dibutuhkan adalah downtime dan loading time. Pengukuran waktu adalah pekerjaan mengamati dan mencatat waktuwaktu kerjanya baik setiap elemen ataupun siklus dengan menggunakan alat-alat yang telah disiapkan (Rafian dan Muhsin, 2017).

Performance adalah rasio yang menunjukkan kemampuan dari peralatan dalam menghasilkan barang. Data yang dibutuhkan adalah total produksi, cycle time, dan operation time, Rate of Quality adalah rasio yang menunjukkan kemampuan dari peralatan dalam menghasilkan barang. Data yang dibutuhkan adalah total produksi, cycle time, dan operation time, Perhitungan overall equipment effectiveness (OEE), yang diperoleh dari hasil perkalian ketiga kategori tersebut.

Pemeliharaan memuncukan usulan waktu perawatan berdasarkan kondisi spare part dan tingkat kekritisan (Iriani, 2011), yaitu maintenance merupakan suatu kegiatan untuk memelihara atau menjaga peralatan produksi pada suatu industri dan mengadakan perbaikan maupun penyesuaian serta penggantian. Dengan mengetahui hal tersebut, perusahaan juga dapat melakukan perbaikan atau pencegahan kerusakan yang mungkin akan terjadi agar dapat meningkatkan produktivitas (Ningrum and Muhsin, 2016)

Analisis OEE menyoroti 6 kerugian utama (six big losses) penyebab peralatan produksi tidak beroperasi secara normal. Dari 6 kerugian utama dikelompokkan menjadi 3 yaitu downtime losses, speed losses, quality losses. Diagram pareto untuk menunjukkan perbandingan data masalah dengan data secara 
keseluruhan, prinsip diagram pareto dikenal sebagai aturan 80/20 dengan melakukan 20\% dari pekerjaan bisa menghasilkan $80 \%$ manfaat. Diagram sebab akibat untuk membuat hipotesis rantai penyebab dan akibat dan mengorganisasikan hubungan antar variabel.

Tipe produk cacat pada mesin auto hanger, yaitu produk cacat karena foto, produk cacat karena timbangan labil, dan produk cacat karena rusak. Produk cacat karena foto disebabkan oleh karena lembaran sachet yang dipotong tidak menghasilkan produk sachet yang proporsional

\section{PENGOLAHAN DATA}

\subsection{Data Komponen Kritis}

Data yang digunakan merupakan data historis waktu operasi mesin, data downtime mesin, data produksi produk. Data waktu operasi pada mesin auto hanger dapat dilihat pada Tabel 1.

Perhitungan Overall Equipment Effectiveness (OEE) harus diawali dengan perhitungan sebagai berikut:

a. Perhitungan Availability (Tabel 2) yaitu sebagai berikut:

Operating Time $=$ Loading Time-Downtime Availability $=($ Operating Time $) /($ Loading Time $) \times 100 \%$

b. Perhitungan Performance Efficiency (Tabel 3) untuk yaitu sebagai berikut:

Menghitung ideal cycle time dengan rumus Ideal Cycle Time $=($ loading time $) /$ plan

c. Perhitungan Rate of Quality (Tabel 4) yaitu sebagai berikut:

Rate of Quality $=($ processed amount-defect amount $) /($ processed amount $) \times 100 \%$

Tabel 1. Data operasi mesin auto hanger

\begin{tabular}{ccccccc}
\hline \multirow{2}{*}{ Periode } & \multicolumn{5}{c}{ Mesin Auto Hanger } \\
\cline { 2 - 7 } & $\begin{array}{c}\text { Loading } \\
\text { time }\end{array}$ & Downtime & $\begin{array}{c}\text { Operating } \\
\text { Time }\end{array}$ & $\begin{array}{c}\text { Actual } \\
\text { Output }\end{array}$ & $\begin{array}{c}\text { Product } \\
\text { Demand }\end{array}$ & $\begin{array}{c}\text { Plan } \\
\text { (kardus) }\end{array}$ \\
\hline 01 & 8 & 2.13 & 5.87 & 236 & 930 & 256 \\
02 & 21.5 & 1.17 & 20.33 & 518 & 786 & 536 \\
03 & 24 & 1.2 & 22.8 & 496 & 1295 & 536 \\
04 & 24 & 1.12 & 22.88 & 510 & 1000 & 536 \\
05 & 24 & 2.33 & 21.67 & 508 & 778 & 536 \\
\hline
\end{tabular}

Tabel 2. Availability

\begin{tabular}{ccccc}
\hline \multirow{2}{*}{ Periode } & \multicolumn{4}{c}{ Mesin Auto Hanger } \\
\cline { 2 - 5 } & Loading & Downtime & Operating & Availability \\
\hline 01 & 8 & 2.13 & 5.87 & 73.38 \\
02 & 21.5 & 1.17 & 20.33 & 94.56 \\
03 & 24 & 1.2 & 22.8 & 95 \\
04 & 24 & 1.12 & 22.88 & 95.3 \\
05 & 24 & 2.33 & 21.67 & 90.29 \\
\hline
\end{tabular}

Tabel 3. Performance efficency

\begin{tabular}{ccccccc}
\hline \multirow{2}{*}{ Periode } & \multicolumn{5}{c}{ Mesin Auto Hanger } \\
\cline { 2 - 7 } & $\begin{array}{c}\text { Operating } \\
\text { time }(\mathbf{j a m})\end{array}$ & $\begin{array}{c}\text { Output aktual } \\
\text { (kardus) }\end{array}$ & $\begin{array}{c}\text { Plan } \\
\text { (kardus) }\end{array}$ & $\begin{array}{c}\text { Ideal } \\
\text { (cycle time) } \\
\text { jam }\end{array}$ & $\begin{array}{c}\text { Actual } \\
\text { cycle time }\end{array}$ & $\begin{array}{c}\text { Performance } \\
\text { efficiency }(\%)\end{array}$ \\
\hline 01 & 5.87 & 236 & 256 & 0.031 & 0.025 & 100 \\
02 & 20.33 & 518 & 536 & 0.04 & 0.039 & 100 \\
03 & 22.8 & 496 & 536 & 0.045 & 0.046 & 97.49 \\
04 & 22.88 & 510 & 536 & 0.045 & 0.045 & 99.89 \\
05 & 21.67 & 508 & 536 & 0.045 & 0.043 & 100 \\
\hline
\end{tabular}


Tabel 4. Rate of quality

\begin{tabular}{ccccccc}
\hline \multirow{2}{*}{ Periode } & \multicolumn{1}{c}{ Actual } & \multicolumn{4}{l}{ Product Defect } & \multirow{2}{*}{$\begin{array}{c}\text { Rate of } \\
\text { Quality }\end{array}$} \\
\cline { 2 - 6 } & $\begin{array}{c}\text { Output } \\
\text { (sachet) }\end{array}$ & Rusak & Foto & Labil & Total & 99.77 \\
\hline 01 & 408738 & 369 & 421 & 140 & 930 & 99.91 \\
02 & 895890 & 416 & 370 & & 786 & 99.85 \\
03 & 858383 & 992 & 303 & 0 & 1295 & 99.89 \\
04 & 882280 & 650 & 350 & 0 & 1000 & 99.91 \\
05 & 878602 & 425 & 353 & 0 & 778 & \\
\hline
\end{tabular}

Tabel 5. Overall equipment effectiveness

\begin{tabular}{ccccc}
\hline Periode & Availability $(\%)$ & $\begin{array}{c}\text { Performance } \\
\text { Efficiency }(\%)\end{array}$ & $\begin{array}{c}\text { Rate of } \\
\text { Quality } \\
(\%)\end{array}$ & $\begin{array}{c}\text { Overall Equipment } \\
\text { Effectiveness }(\%)\end{array}$ \\
\hline 01 & 73.38 & 100.00 & 99.77 & 73.21 \\
02 & 94.56 & 100.00 & 99.91 & 94.48 \\
03 & 95.00 & 97.49 & 99.85 & 92.47 \\
04 & 95.33 & 99.89 & 99.89 & 95.12 \\
05 & 90.29 & 100.00 & 99.91 & 90.21 \\
\hline
\end{tabular}

Tabel 6. Nilai six big losses

\begin{tabular}{|c|c|c|c|c|c|c|}
\hline \multirow[b]{2}{*}{ No } & \multirow{2}{*}{$\begin{array}{c}\text { OEE } \\
\text { Faktor }\end{array}$} & \multirow{2}{*}{\multicolumn{2}{|c|}{ Kerugian Besar }} & \multicolumn{3}{|c|}{ Mesin Auto Hanger 1} \\
\hline & & & & $\begin{array}{c}\text { Total Waktu } \\
\text { Kerugian }\end{array}$ & Presentase & Kumulatif \\
\hline \multirow{2}{*}{1} & \multirow{2}{*}{ A } & Downtime & $\begin{array}{l}\text { Equipment } \\
\text { Failure }\end{array}$ & 7 & $3,64 \%$ & $3,64 \%$ \\
\hline & & Losses & $\begin{array}{c}\text { Setup \& } \\
\text { Adjustment }\end{array}$ & 17 & $8,85 \%$ & $12,49 \%$ \\
\hline 2 & $\mathrm{P}$ & Speed Losses & $\begin{array}{l}\text { Iddle \&Minor } \\
\text { Stoppage } \\
\text { Reduced Speed }\end{array}$ & 162,64 & $84,64 \%$ & $97,13 \%$ \\
\hline \multirow[t]{2}{*}{3} & \multirow[t]{2}{*}{ Q } & Deffect & Deffect Losses & 5,505 & $2,87 \%$ & $100 \%$ \\
\hline & & Losses & Reduced Yield & 0 & $0 \%$ & $100 \%$ \\
\hline
\end{tabular}

d. Perhitungan Overall Equipment Effectiveness (Tabel 5) yaitu sebagai berikut: $O E E=$ Availability $x$ Performance Efficiency $x$ Rate of Quality

e. Perhitungan Six Big Losses (Tabel 6), kerugian dari Equipment Failure berupa kerusakan bagian mesin seperti pada pisau mesin, sensor detected empty, vacuum error, dan mesin sealer rusak.

Six big losses memiliki beberapa jenis kerugian pada mesin auto hanger diantaranya kerugian downtime losses terdiri dari waktu equipment failure.

f. Membuat diagram pareto (Gambar 1) untuk mengelompokkan jumlah kerugian waktu yang dihasilkan pada mesin auto hanger. g. Membuat Fishbone Diagram, kerugian waktu terbesar dihasilkan dari indikator speed losses untuk ketiga mesin auto hanger, yaitu sekitar $85 \%$. Untuk itu dapat diklasifikasikan faktor-faktor yang mempengaruhi indikator speed losses yang dapat dilihat pada Gambar 2.

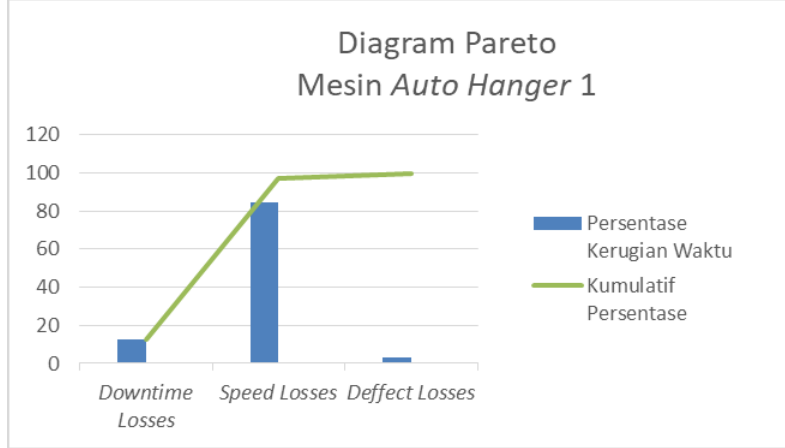

Gambar 1. Diagram pareto mesin hanger 


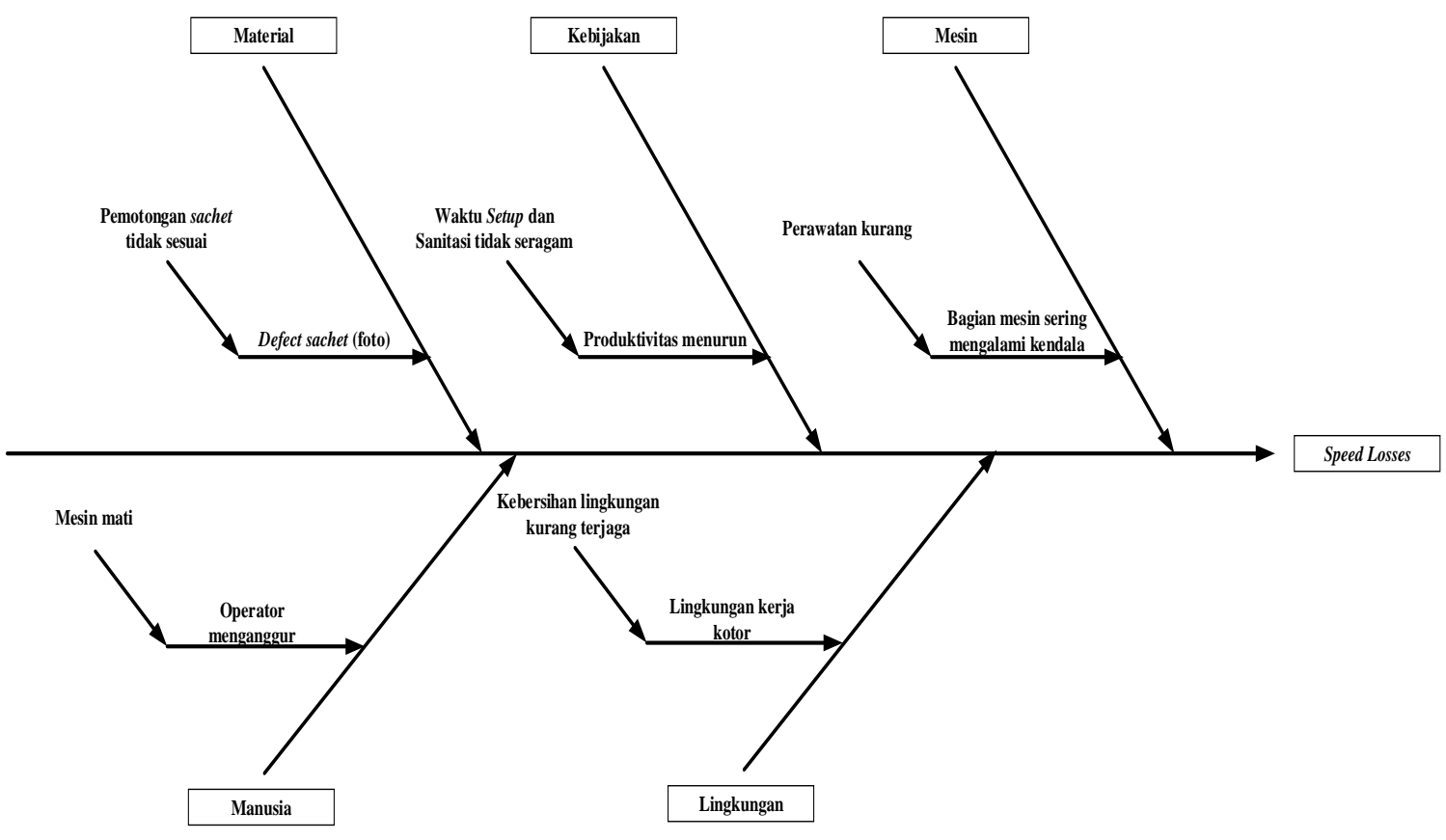

Gambar 2. Fishbone diagram auto hanger

Persentase kerugian terbesar untuk jenis kerugian six big losses, yaitu speed losses yang ditentukan oleh beberapa penyebab yang dapat dianalisis menggunakan fishbone diagram.

\section{KESIMPULAN}

Berdasarkan penelitian yang telah dilakukan diperoleh kesimpulan, yaitu (a) Berdasarkan perhitungan overall equipment effectiveness pada ketiga mesin belum mencapai standar world class, yaitu > 85\%. Nilai availability pada ketiga mesin juga masih belum memenuhi standar world class, yaitu > $90 \%$. Nilai performance of rate pada ketiga mesin juga masih belum memenuhi standar world class, yaitu > 95\%. Nilai availability pada ketiga mesin juga masih belum memenuhi standar world class, yaitu > 99\%. Sehingga diperlukan usulan perbaikan agar dapat meningkatkan produktivitas. (b) Berdasarkan pengolahan data overall equipment effectiveness maka nilai terendah terletak pada nilai availability yang disebabkan oleh berbagai faktor downtime. Sementara pada pengolahan data six big losses didapatkan kerugian terbesar pada speed losses. Hal ini saling terkait satu sama lain karena adanya kendala pada mesin yang menyebabkan mesin berhenti sehingga target produksi tidak tercapai dengan maksimal.

Metode overall equipment effectiveness tidak hanya dapat digunakan pada suatu departemen khusus saja, namun juga dapat digunakan untuk departemen lain pada mesin lain. Metode ini dapat dikombinasikan dengan metode maintenance lainnya untuk masalah komplkes agar mendapat analisis yang lebih akurat.

\section{DAFTAR PUSTAKA}

Bangun, I. H., Rahman, A., \& Darmawan, Z. (2014). Perencanaan Pemeliharaan Mesin Produksi Dengan Menggunakan Metode Reliability Centered Maintenance ( $\mathrm{Rcm}$ ) II Pada Mesin Blowing Om (Studi Kasus: PT Industri Sandang Nusantara Unit Patal Lawang). Jurnal Rekayasa dan Manajemen Sistem Industri, 2(5), p997-1008.

Iriani, Y., \& Rahmadi, E. S. (2011). Usulan Waktu Perawatan Berdasarkan Keandalan Suku Cadang Kritis. 6th National Industrial Engineering Conference (NIEC-6), Universitas Widyatama, Surabaya.

Muhsin, A. (2016). Analisis Performansi Departemen Machinning Menggunakan Metode Overall Equipment Effectivenes (Oee)(Studi Kasus pada Perusahaan Pengecoran Logam Xyz). Opsi, 9(01), 16-23. 
Ningrum, N. S., \& Muhsin, A. (2016). Analisis Efisiensi dan Efektivitas Performansi Line Machining Propeller Shaft untuk Produk Flange Menggunakan Metode Overall Equipment Effectiveness (Oee). Opsi, 9(2), 109-118.

Rafian, M. A., \& Muhsin, A. (2017). Analisis

Beban Kerja Mekanik pada Departemen Plant dengan Metode Work Sampling (Studi Kasus pada PT Xyz). Opsi, 10(1), 35-42.

Ristyowati, T., Muhsin, A., \& Nurani, P. P. (2017). Minimasi Waste Pada Aktivitas Proses Produksi Dengan Konsep Lean Manufacturing (Studi Kasus di PT. Sport Glove Indonesia). Opsi, 10(1), 85-96.

Wahyuni, M. F. Analisis Nilai Overall Equipment Effectiveness (Oee) sebagai Dasar untuk Perbaikan Efektivitas Kerja Mesin Cut Off di Plant X PT ABC. Jurnal Ilmiah Universitas Bakrie, 3(02). 